\title{
La disputa por las identidades étnicas en el cine mexicano contemporáneo.
}

\section{The Dispute over Ethnic Identities in Contemporary Mexican Cinema.}

\section{Resumen}

En el artículo se analiza en qué medida el cine mexicano reciente, tanto el de ficción como el documental, han ido transformando su discurso sobre las identidades étnicas durante los últimos años. A partir de una metodología interdisciplinaria que articula las categorías de análisis cinematográfico con las de los estudios antropológicos y sociales, se trata de mostrar algunos intentos por descolonizar la mirada sobre los pueblos indígenas en el cine de ficción, así como las diversas tendencias presentes en el cine documental que van, desde entender lo étnico como reproducción cultural hasta plantear los procesos de resistencia y de la transformación de las identidades.

Palabras claves

Identidades étnicas, cine, reproducción social, resistencia.

\begin{abstract}
The article analyzes the extent to which recent mexican cinema, both fiction and documentary, have been transforming their discourse on ethnic identities in recent years. Based on a interdisciplinary methodology that articulates the categories of cinematographic analysis with those of anthropological and social studies, it tries to show some attempts to decolonize the view of indigenous peoples in fiction cinema, as well as the diverse tendencies present in the documentary film ranging from understanding the ethnic as cultural reproduction to raising the processes of resistance and the transformation of identities.
\end{abstract}


CATEDRAL TOMADA: Revista de crítica literaria latinoamericana / Journal of Latin American Literary Criticism La disputa por las identidades étnicas en el cine mexicano contemporáneo.

\section{Introducción.}

El concepto de la identidad está debatiéndose intensamente dentro del amplio campo de las ciencias sociales. Parecería que se trata de un concepto más confuso y contradictorio de lo que se había pensado antes de que las luchas decoloniales $^{1}$ y el debilitamiento de los Estados nación pusiera de nuevo el término en serios aprietos. Junto con la crisis del propio concepto surgió el problema de su representación: porque la identidad tal como fue inventada por la modernidad, la del individuo y, más tarde, la de la nación, siempre requirió de las representaciones ya sea a través de la literatura, de la pintura, del teatro, de la fotografía, de la música y desde los fines del siglo XIX, del cine.

La historia de las representaciones de la identidad individual y nacional no ha sido lineal. En un principio, la figura del individuo dotaba de sentido a todo el sistema económico, político e ideológico burgués. Era, en efecto, el individuo el sujeto de la organización económica capitalista, de su sistema jurídico y político y de su ideología. El arte inmediatamente adaptó esta tendencia. El auge del retrato en la pintura, la psicología y el carácter del personaje en la novela y del teatro, contribuyeron a instalar en el imaginario social la figura del sujeto individual.

Tal como explica Grüner, a partir del Romanticismo, la figura del individuo se trasladó también a las sociedades, a la necesidad que tenía la burguesía de inventar el "estado nacional” en el que todos los integrantes pudieran reconocerse simbólicamente en una cultura, una lengua y una tradición comunes (Grüner 59).

A su vez, la necesidad del capitalismo de expandirse mundialmente generó el colonialismo por parte de los países europeos que

no sólo supuso el más gigantesco genocidio de la historia humana, sino un igualmente gigantesco etnocidio, con el arrasamiento de lenguas y

1 Las luchas decoloniales han sido conceptualizadas por diversos autores. Para el tema de la transformación (o reinvención) de los Estados y, por lo tanto, de las identidades asociadas al moderno Estado- nación, consúltese (Santos 157-179). 
culturas a veces milenarias, y su sustitución forzada por la lengua, la cultura y la religión del Estado metropolitano, así como el invento de "naciones" virreynales -y luego, tras la descolonización de "naciones" supuestamente soberanas- allí donde había otras formas de organización política, territorial, cultural. ( Grüner 59)

Las guerras de la independencia no alteraron mayormente esta situación, puesto que fueron dirigidas $\mathrm{y}$ ganadas por las elites afines a sus antiguas metrópolis. En América Latina en general, y en México en particular, la identidad nacional ha sido objeto de un debate permanente. Fue el patriotismo criollo el que definió, en un inició los ingredientes fundamentales de la identidad nacional: la exaltación del pasado indígena, el repudio de la Conquista y del españolismo, y la devoción por la Guadalupana (Brading 15). Las disputas entre los conservadores y liberales inclinaron la balanza en favor de estos últimos y permitieron el afianzamiento de un Estado basado en la separación de la Iglesia, la división de los poderes y una amplia difusión de la idea del nacionalismo basado, sobre todo después de la Revolución mexicana, en la idea del mestizaje, de la mexicanización del indio y en el sincretismo cultural. El Estado posrevolucionario usó la identidad cultural para generar el consenso, por encima de las diferencias y conflictos de clase. Para ello no sólo dotó de contenidos nacionalistas los planes y programas de estudio de las escuelas en todos los niveles, sino también se volvió mecenas de los artistas, lo mismo pintores, compositores, músicos, escritores que cineastas. En el cine, que es el tema de nuestro interés, el nacionalismo dejó una profunda huella mientras el Estado era el principal agente del financiamiento del mismo, es decir prácticamente hasta fines de la década de 1980 (Arroyo 75-92; Barrios 217-250; Jablonska 93-113).

Hoy, sin embargo, han surgido nuevas formas de la relación entre lo individual y lo colectivo, así como entre las colectividades particulares y las de mayor alcance. La caída del Muro de Berlín, la tercera revolución tecnológica, la globalización económica y los procesos concomitantes (revolución en las 
comunicaciones, migraciones, debilitamiento de los Estados- nación) son señalados por muchos autores como elementos responsables de esta transformación. Lo anterior, a su vez, ha influido en las identidades: algunas fueron debilitándose, otras fueron reinventándose o incluso, transformándose. La desestabilización y la deconstrucción de las identidades tradicionales permitió comprender, lo que ya habían anticipado algunos teóricos: que la identidad no era algo original, unificado e integral (Valenzuela; Giménez; Maalouf).

Como se ha señalado en diversas ocasiones, las identidades son cambiantes y, necesariamente, relacionales, es decir, un actor social emerge y se afirma sólo en la confrontación con otras identidades en el proceso de interacción social. Pero ello no implica la conformación de un sistema relacional coherente. En los tiempos de modernidad tardía, argumenta Stuart Hall, las identidades están cada vez más fragmentadas y fracturadas, "se constituyen de múltiples maneras a través de discursos, prácticas y posiciones diferentes, a menudo cruzadas y antagónicas” (Hall 17).

Las identidades se constituyen dentro de la representación y no fuera de ella, es decir, a partir de cómo nos representan "otros", y del proceso de autorrepresentación. Emergen en el juego de las modalidades específicas de poder y por eso, son más producto de la diferencia y de la exclusión, que de la continuidad naturalmente conformada (18). Por ello, la identidad cultural es un acto de poder porque siempre excluye algo y establece una jerarquía violenta entre los dos polos. En esta jerarquía el segundo término queda reducido a un accidente, en oposición al carácter esencial del primer polo (20).

La representación es el mecanismo mismo de la construcción de la identidad. El término “representación”, como explica Grüner, es polisémico, dado que pertenece tanto al discurso de la política, como al de la estética, de la teoría del arte o la filosofía de las formas simbólicas (Grüner 61). La cuestión central de la representación es que pone en juego lo presente y lo ausente, o en otras palabras, lo visible y lo invisible, donde lo invisible es parte constitutiva de lo visible. 
En realidad, hablar de la representación no es correcto: más bien asistimos a las representaciones en disputa, por un lado, las que producen las instancias culturales ligadas al poder del Estado, y por el otro lado las representaciones marginales que buscan ofrecer versiones distintas a las oficiales para lograr la visibilidad y el reconocimiento social.

¿Cómo ha operado este proceso en el cine mexicano ${ }^{2}$ De una manera similar a la descrita arriba. El cine hecho en México o por los mexicanos ha pasado de representar a caracteres individuales y fuertemente estereotipados (Barrios; Jablonska), vinculados con la historia nacional a aventurarse en el proceso de desestabilización de los personajes con identidades establecidas y tradicionales, a mostrar el debilitamiento de las adhesiones antiguas (nación, catolicismo, familia) y la liquidez, carácter hibrido, inestable y liminal.

En las últimas tres décadas, por lo menos, el cine hecho en México ha participado intensamente en las disputas por la representación de las identidades colectivas: las étnicas, las de género y las de otros sectores sociales, como los migrantes.

El discurso cinematográfico ha ido cambiando no sólo en cuanto al contenido sino también en cuanto a la forma, elementos que iré señalando en el análisis de las películas concretas.

\section{Las identidades étnicas en el cine del siglo XXI.}

El tema de las identidades étnicas no es nuevo para el cine mexicano. Hasta el fin del siglo XX, las ficciones más que de etnias hablaban de "los indígenas", individuos idealizados cuando pertenecían a las culturas antiguas (Bartolomé de las Casas, Sergio Olhovich, 1992; El jardín de tía Isabel, Felipe Cazals, 1971; La otra conquista, Salvador Carrasco, 1998; Cabeza de Vaca,

2 Actualmente existe una amplia disputa acerca de si es válido hablar todavía de los cines nacionales, cuando muchas veces los filmes son co- producidos por los capitales provenientes de diversos países y los equipos de filmación pueden ser también trasnacionales (Williams). 
Nicolás Echevarría, 1990) o bien, representados como los más pobres de los pobres y oprimidos por clases sociales más privilegiadas, mestizas o blancas (Macario, Roberto Gavaldón, 1959; Balún Canán, Beniro Alazraki, 1977).

Los documentales producidos bajo la etiqueta de "etnográficos" por lo general se filmaban por iniciativa y bajo los auspicios de las instituciones del Estado. Una de ellas fue la Secretaría de la Educación Pública (SEP) que en 1976 inició un proyecto coproducido por Centro de Producción de Cortometraje, Cine Difusión y National Film Board of Canada: Etnocidio, notas sobre el Mezquital, dirigida por Paul Leduc, en el que se explicaba la explotación y la aculturación de los otomíes de Mezquital. (Ochoa 89). El Instituto Nacional Iindigenista (INI), en 1978 inició la producción de películas etnográficas, con diversas temáticas y abordajes. Entre éstas estaban Jícuri Nierra: la danza del peyote (1980) de Carlos Kleiman y Peleas de tigres: una petición de lluvia nahua (1987) de Alfredo Portilla y Alberto Becerril (Ochoa 90).

Alberto Becerril, quien trabajo en el Archivo Etnográfico Audivisual del propio INI entre 1984 y 1987 como investigador, realizador, post- productor y Jefe del Archivo tiene una visión muy crítica de esos filmes. En los años 70:

La manera en que los miembros de las comunidades indígenas en que se había trabajado percibían la película realizada simple y sencillamente no era relevante ni para el cineasta, ni en general, para el antropólogo. Las películas "sobre los pueblos indígenas en México" eran y siguen siendo en la mayoría de los casos, valoradas, evaluadas, clasificadas y premiadas por etnógrafos, antropólogos y cineastas. Hasta el día de hoy, es poco común que los jurados de festivales sobre cine indígena sean miembros de los pueblos donde se trabajó. (Becerril 32)

Otros ensayos preliminares dieron lugar a la creación del programa de Transferencia de Medios Audiovisuales a Comunidades y Organizaciones Indígenas (TMA) en 1989. Este programa permitió que los individuos y grupos 
fueran apropiándose del video y en estados con mayor presencia indígena empezaron a surgir iniciativas locales, en ocasiones en colaboración con instancias de producción independiente u otras, como universidades y gobiernos de los estados para registrar eventos importantes desde su punto de vista: ritos, tradiciones, asambleas, marchas de protesta, conflictos (Ávila 386).

Mientras las instancias gubernamentales procuraban documentar algunos elementos de la vida de los pueblos indígenas desde una visión etnográfica oficialista, colectivos como Ojo de Agua Comunicación empezaron a independizarse con un claro propósito político: apoyar la construcción de la autonomía de los pueblos, fortalecer su lucha por los derechos, avalar y conservar su propia cultura y producir información desde su punto de vista.

Fue a fines del siglo XX, cuando experimentamos en toda América Latina el resurgimiento de las etnicidades. En México, lo que cimbró la conciencia sobre la importancia de este tema fue el levantamiento de EZLN en 1994 y la firma de los acuerdos de San Andrés Larráinzar entre los "rebeldes" y el gobierno mexicano. Por el otro lado, el propio gobierno, además de la presión de los pueblos indígenas, firmó documentos internacionales, el Acuerdo 169 de la Organización Internacional de Trabajo (OIT) principalmente, que lo obligaban a cambiar su relación con las etnias.

Todo ese conjunto de factores provocó un amplio debate académico acerca de la noción de la identidad étnica y su relación con otras pertenencias: la nacional, la regional, la de género y de clase. ${ }^{3}$ Paulatinamente se fue abandonando

${ }^{3}$ Resumir este debate no es el objetivo de este artículo, pero voy a señalar los hitos más importantes. El término "etnicidad" apareció en las ciencias sociales en la década de 1950 y fue introducido por el sociólogo estadounidense David Reisman. En cambio, el vocablo "etnia" es muy antiguo. El uso de ambos términos ha tenido siempre una connotación discriminatoria y excluyente, es decir han servido para designar a los demás y no al grupo que los clasifica de este modo desde una posición dominante (Giménez 36). En los estudios antropológicos anteriores a 1970 predominaba la visión esencialista de la cultura y de la etnia, que asumía que ambas tenían ciertos rasgos invariables, derivados de un pasado común (Thompson 190-198). Esta concepción estaba asociada con la idea de la "reproducción cultural" conforme a la cual, las etnias y sus culturas no debían "contaminarse" en el contacto con otras culturas sino conservar su supuesta "pureza". Fue a partir de la década de 1970 cuando se abrió el debate sobre estos conceptos, a partir del principio sociológico de la determinación reciproca de los grupos sociales. En consecuencia los grupos étnicos empezaron a verse como "entidades que surgen de la 
la idea de una identidad esencial e inamovible, de alguna manera contenida en la noción de "pueblos originarios". No es que antes no se señalara ya la falacia de esta creencia (Friedlander), sino que ahora empezó a aceptarse casi universalmente que las pertenencias étnicas son necesariamente dinámicas y negociadas. También se fue abandonando la idea de que las etnias debían ser definidas por las distintas agencias del Estado, en su lugar empezaron a buscarse las formas para qué estas se basen en la autoadscripción y en el "egorreconocimiento" (Terrén 46). Otro cambio se produjo cuando los autores reconocieron que hablar de las etnias no podía reducirse a las referencias culturales sino a cuestiones sociales que incluyen su participación económica y política, vale decir la división cultural del trabajo y las relaciones de poder dentro del grupo y frente a otros poderes, presentes en su territorio.

El cambio de perspectiva no es menor: en vez de estudiar "la reproducción cultural" y "la herencia", hay que reconocer que "las personas [...] tienen la capacidad de crear nuevas circunstancias, generar nuevas formas de definir el mundo, inventar nuevas tecnologías e instituciones que alteran los estilos de vida y debilitan radicalmente los sistemas de valores tradicionales" (Weinreich cit. por Terrén 48).

Como decíamos antes, todas las identidades son relacionales, y las étnicas no son una excepción. Una etnia toma conciencia de su particularidad cuando entra en contacto con la otra.

Y finalmente, para esta investigación es muy importante subrayar el carácter discursivo de la sociedad. Ello implica, para el caso de la etnicidad "tomar conciencia de la complejidad y sesgo implícito en todo acto de representación" (Terrén 48). También las películas son discursos, pero discursos sui generis a medida que comunican simultáneamente a través de varios registros y recursos expresivos: en lo que a la imagen se refiere, tienen importancia, los

diferenciación cultural- subjetivamente elaborada y percibida- entre grupos que interactúan en un contexto determinado de relaciones interétnicas" (Giménez 39). Véase también Gutiérrez y Balsley. 
planos y los encuadres, los movimientos de la cámara y la edición. Pero de la imagen visual no puede separarse lo que ocurre en la banda sonora donde se registran los ruidos, los diálogos y la música.

La pregunta más difícil cuando analizamos las películas a partir de la perspectiva de la representación de las identidades es acerca del punto de vista desde el que se construye ésta. ¿Es éste externo, impuesto por el equipo de filmación, o interno, generado por los miembros de un grupo de autodescripción? Aunque en el caso de filmes de ficción, la pregunta puede parecer absurda, como veremos más adelante, no necesariamente lo es. Algunos cineastas intentan acercarse lo más posible a las vivencias y formas de ver el mundo de las etnias que retratan. Desde luego, es muy probable que, si lo logran, sólo lo hacen parcialmente. Pero lo mismo ocurre con los documentales, en los que las opiniones y expresiones de "la gente" son mediadas por la cámara, el equipo del sonido y, por último, por la edición final, en que los participantes de la película casi nunca participan.

De alguna manera, en algunos casos es notorio el esfuerzo por construir una representación más dialógica y descentrada, en otros, sin embargo, es el equipo fílmico el que se asume como el capaz de definir la identidad del otro.

\section{El cine de ficción y los intentos de descolonizar la mirada. ${ }^{4}$}

Las películas que analizo en los siguientes apartados fueron seleccionadas con dos criterios laxos. Por un lado, se trata exclusivamente de películas mexicanas ${ }^{5}$ producidas después del año 2000. Por el otro lado, se trata de los

\footnotetext{
${ }^{4}$ La mirada que ha colonizado las culturas diferentes a la europea es la que las coloca en un plano de inferioridad frente a la que le ha pertenecido al colonizador. Por ello "descolonizar la mirada" significa ver y comprender las culturas indígenas desde otro lugar, el de estos mismos pueblos.

${ }^{5}$ El término "películas mexicanas" se ha vuelto problemático en este siglo, a medida que el Estado prácticamente se retiró de la producción, distribución y exhibición de los filmes. De manera que en este artículo me referiré a las películas filmadas en el territorio mexicano, que tratan las problemáticas relacionadas con las etnias asentadas en dicho territorio.
} 
filmes que han tenido cierta resonancia entre el público del país y que han participado en la disputa por las identidades étnicas.

El método de análisis articula diferentes categorías, tanto las provenientes de la antropología, como la cultura, la etnia, el mito y el símbolo (Durand), como las que provienen de la estética de la imagen y el sonido ${ }^{6}$ (Aumont et.al.), como de la teoría narratológica: el narrador, el punto de vista, la construcción del personaje, del tiempo y espacio (Canet y Prósper). Asumimos siempre, que las películas son productos culturales y que en su interpretación se negocian temas relativos a dominación, poder, ideología, subordinación y hegemonía. Están categorías de análisis están implícitas en la interpretación de los filmes, para hacer la lectura más ligera y abocada principalmente al tema del artículo: la participación del cine mexicano en la disputa por las identidades.

Juliano Gonçalves da Silva, partiendo de una perspectiva antropológica, considera que las películas de ficción mexicanas, y entre ellas Cochochi y Corazón del tiempo, que voy a analizar más adelante, constituyen un esfuerzo por descolonizar los imaginarios culturales globales. Tal vez, en parte tenga razón, sobre todo en el caso de Cochochi, donde coincido en que se intenta construir una mirada diferenciada sobre las etnias mexicanas y reinterpretarlas a partir de los elementos de estas culturas y de su visión del mundo (Gonçalves 105). Sin embargo, considero que la segunda de las películas fracasó rotundamente en este intento. Enseguida explicaré por qué.

Corazón de tiempo (2008), dirigida por Alberto Cortés y con el guion escrito por Hermann Bellinghausen ${ }^{7}$ junto con el director, es una película que deja el tema étnico de lado - no se nombra ninguna de las etnias que habitan el

${ }^{6}$ El análisis estético comprende la interpretación de la imagen, dentro de la cual se toman en consideración elementos tales como el color, la iluminación, la composición, la profundidad de campo, así como el emplazamiento, participación y movimiento de la cámara, entre otros; el sonido, donde se tiene en cuenta la música, las voces, los silencios, los ruidos, las relaciones entre el sonido y la imagen, etcétera; el montajeledición, entendido como como el procedimiento de articulación y configuración del relato, en el que se analiza la relación secuencial entre imágenes, es decir, la duración y ritmo de las tomas, la sucesión de imágenes entre secuencias, los tipos de montajes, entre otros.

${ }^{7}$ Hermann Bellinhausen fue reportero del periódico La Jornada en Chiapas durante varios años. Por esta razón se le reconocía como un gran conocedor del tema. 
territorio zapatista, no se habla en ninguna de las lenguas propias de los tzotziles, tzleltales, tojolabales, mames, choles o zoques- por contarnos una historia de amor entre Sonia, una joven que vive en "una comunidad de apoyo"8 y Julio, un chico que forma parte del ejército insurgente y vive en las montañas. La historia de este amor, más deseado que vivido por los protagonistas, ocupa una gran parte del filme, con el pretexto de que constituye la amenaza para la unidad del grupo, formado por la comunidad y por el ejército, puesto que transgrede sus usos y costumbres. Sonia es formalmente la novia de Miguel, puesto que ha sido "pedida" por su padre. La ceremonia de la "petición" incluye la entrega de una vaca, cosa que disgusta a Sonia que posee una mentalidad hasta cierto punto feminista. Y como el animal se vuelve el símbolo de la poca estima que se le tiene a las mujeres en las sociedades tradicionales, aparece constantemente en el filme.

La actitud de Sonia, quien reclama ser dueña de sus propias decisiones aunque sin muchos argumentos-, podría representar, entonces el carácter cambiante de las identidades. Su abuela, quien en secreto es su aliada, funge como la memoria del pueblo que huyó de un patrón que los maltrataba y volvió a huir del ejército federal cuando éste atacó a las posiciones del ejército rebelde. Ella cree en la necesidad de oponerse a la injusticia social, que su pueblo ha sufrido y considera legítimas las distintas formas de desobediencia, incluida la que ejerce su nieta, Sonia.

En la película, que definitivamente apostó por "el feminismo", aparecen otras dos mujeres y una niña. La madre de Sonia, desempeña un papel tradicional en la familia. La hermanita menor de la malograda novia tiene la función de provocar a la abuela para que cuente las historias del pueblo, con la "natural" curiosidad propia de su edad, y a vez es un símbolo de una "identidad en proceso de construcción". De ahí sus constantes preguntas sobre el pasado de la abuela y las acciones de su hermana, acompañadas reiteradamente de secuencias en que la niña mira su reflejo en el agua o en un espejo.

8 "Comunidades de apoyo" son las que se identifican con las causas del EZLN y organizan la vida cotidiana bajo los principios de autonomía y resistencia al "mal gobierno", pero sus integrantes no pertenecen al ejército "rebelde". 
Finalmente, es muy significativo que el puesto del mando máximo en el ejército zapatista lo desempeñe una mujer "la capitán”. En la película su función consiste en cuidar que las relaciones entre la comunidad del apoyo y el ejército no se rompan y que se respeten las costumbres ancestrales.

Además de estos temas centrales hay un hilo narrativo que cuenta cómo, gracias al apoyo de los "compañeros" electricistas, se instala la luz en el pueblo. El tema permite, vagamente, plantear la existencia de "leyes revolucionarias" que prohíben la ingesta de alcohol y drogas, mostrar la solidaridad de los trabajadores con los campesinos (el pueblo se dedica a la siembra del maíz) y hacer ver cómo los pueblos logran mejorar en su vida a pesar de estar rodeados por el ejército federal y los paramilitares, que aparecen en la película solo como parte del paisaje.

Hay también un par de secuencias dedicadas a la ocupación de las tierras por el EZLN, y su defensa ante los ataques de "los priistas". ${ }^{9}$ Dicha ocupación no se cuestiona ${ }^{10}$, lo que sí se subraya es la maldad de "los priistas" ("Nos quieren desalojar de nuestras tierras y quemar nuestras casas”) y el espíritu pacífico de la comunidad que evita a toda costa la confrontación ("Se posesionaron los priistas del camino a nuestra milpa... Tuvimos que hacer otro camino, pero tenemos que dar vuelta. Vamos rodeándoles pues para no caer en el enfrentamiento").

Los temas más importantes, tales como las causas del levantamiento del EZLN, sus demandas y aspiraciones, no se representan en la película, sino que se le plantean al espectador mediante una serie de frases escritas sobre la pantalla, después de que termina la narración.

¿Qué tipo de discurso sobre la identidad de los pueblos chiapanecos en que tiene presencia el EZLN construye el filme? Si omitiéramos la explicación final, que tiene un carácter extradiegético, es decir, no forma parte de la historia narrada, se trata de un pueblo fuertemente hispanizado, puesto que no se habla

\footnotetext{
${ }^{9}$ En la región ocupada por los zapatistas, cualquier persona o grupo contrario es llamado "priista".

${ }^{10}$ El diálogo es el siguiente: “¿Y de quién es esta tierra?” "Está tierra es de los zapatistas porque desde 1994 fue tomada por el alzamiento del Ejército Zapatista de Liberación Nacional”.
} 
ninguna de las lenguas originarias, con creciente consciencia feminista, dedicado al cultivo del maíz y a la lucha contra el "priismo" y el ejército federal que lo representa. No hay que ser especialista en el tema para saber que se trata de un discurso muy alejado del que los pueblos de Chiapas construyen sobre sí mismos, tal como puede consultarse en una amplia bibliografía sobre el tema (Baronnet, B. et.al,). En este sentido, afirmo que se trata de una mirada ajena a las etnias a las que pretende "representar".

A diferencia de la película anterior, Cochochi (2009), de Israel Cárdenas y Laura Amelia Guzmán se acerca al universo rarámuri a partir del trabajo con sus propios pobladores. Sus protagonistas son dos hermanos, Luis Antonio y Evaristo, que se representan a sí mismos. La historia que cuenta el filme es muy sencilla: la familia se entera a través de la radio comunitaria que el hermano del abuelo necesita unas medicinas que no se pueden comprar en el lugar en que vive. El abuelo ordena a los hermanos llevar el medicamento, pero se niega a prestarles el caballo, pese a que se trata de un lugar muy alejado. Tony, el niño con más iniciativa que Evaristo, decide tomar el caballo sin permiso. Por el camino se pierden, dejan un rato al caballo mal amarrado y cuando regresan por él, el animal no está. En la búsqueda del caballo también los hermanos se separan. Quien logra entregar la medicina a los familiares y encuentra la manera de citarse con el hermano, usando el servicio del "mensajero de la sierra", servicio que brinda la radio comunitaria, es Evaristo. Así, sus roles cambian. El hermano que parecía menos preparado para enfrentar las responsabilidades, las cumple. Cuando regresan a casa resulta que el caballo había vuelto por sí mismo, y el motivo de la angustia se disipa. Evaristo parece haber madurado con la experiencia y toma el lugar de Tony en la secundaria, aprovechando la beca que se le había otorgado. Este último parece no saber qué hacer con su vida. De lo que sí está seguro es que no le gusta la escuela. 


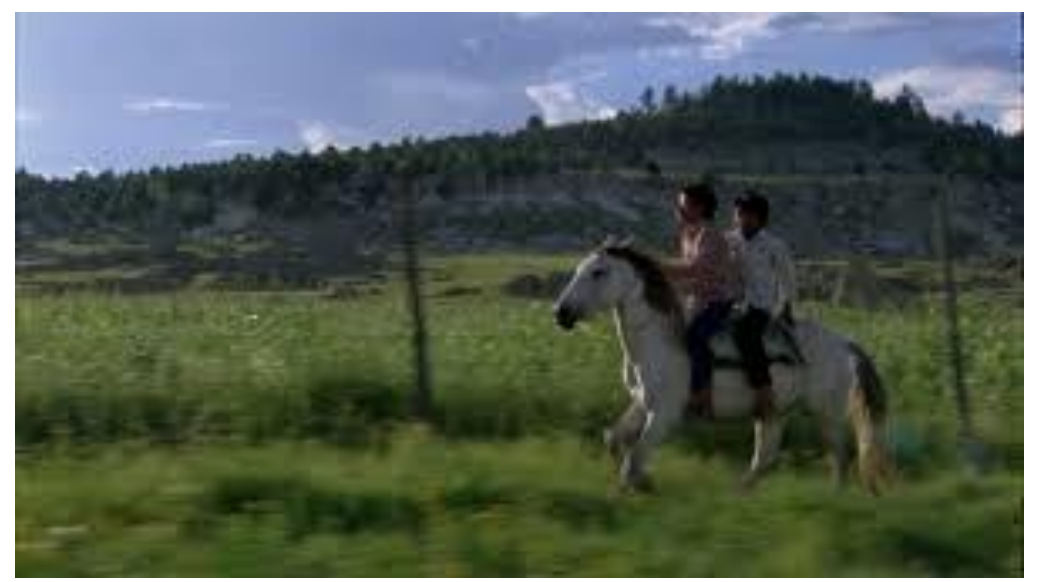

¿Por qué es una película diferente que efectivamente instaura otra mirada sobre las etnias que habitan el territorio de México? En primer lugar, porque la protagonizan los propios rarámuris. Hablan prácticamente todo el tiempo en su lengua (la película se distribuye con subtítulos en español y en inglés) y los diálogos no parecen forzados. La gente que se reúne para preparar e iniciar la "carrera de la bola", ${ }^{11}$ la que dirige las apuestas relacionadas con esta carrera, el ambiente en la fiesta de María Rosa, con la música, el baile y la ingesta de tehuino, ${ }^{12}$ dan la impresión de que se desarrollan con mucha naturalidad, sólo alterada por los escasos diálogos sobre el caballo perdido.

Otro rasgo del filme es que transcurre casi todo el tiempo en los exteriores y permite apreciar la geografía accidentada de la sierra, los valles, las cascadas. En tomas largas y con abundantes planos generales el tiempo transcurre lentamente. Es un tiempo propio de la vida rural y también de un pueblo que vive disperso en un territorio muy vasto. De ahí la importancia de la radio y del servicio de mensajería que presta y que permite que los familiares se comuniquen a gran distancia.

La película abre y cierra mostrando la institución escolar, en un inicio la primaria durante la ceremonia de clausura del ciclo escolar y al final la secundaria

\footnotetext{
${ }^{11}$ Práctica ancestral tarahumara. Vease: http://www.jcarlosmacias.com/autoctonoytradicional/Deportes/Rarajipuami.html

${ }^{12}$ Cerveza de maíz que toman los hombres.
} 
donde Evaristo toma el lugar de Tony, para seguir estudiando. La escuela es representada como un lugar ajeno a la etnia, tanto en el sentido espacial- es por eso que los niños duermen en un albergue-, como en el sentido cultural y simbólico. La ceremonia se desarrolla en español y está organizada conforme al protocolo establecido desde hace muchos años por la SEP. Un discurso hueco del director de la escuela que habla del cierre de una nueva etapa y el inicio de otra, que marcará el futuro de los niños y de la nación, el saludo a la bandera, el inevitable vals que deben bailar los alumnos y algo así como "bailes folclóricos" para amenizar la mañana. El público conformado en su mayoría por las madres y sus otros hijos, mira distraído el espectáculo y aplaude de vez en cuando.

Tony se escapa lo más pronto posible de la ceremonia y ni siquiera se entera que fue distinguido con una beca. La recoge su hermano, guarda el documento en el libro de español ${ }^{13}$ y después entrega la mochila a Tony. Pero éste último no quiere seguir estudiando y avienta con fuerza la mochila, que cae sobre un árbol y ahí queda atrapada hasta que días después, de regreso de la aventura, Tony la rescate para darle la beca a Evaristo.

Aunque ninguna de las películas ha sido filmada por sus protagonistas y es notoria la experiencia cinematográfica de sus autores, sobre todo en el manejo de la cámara y en la edición del filme, sí constituye una novedad en el cine mexicano de ficción, el interés por las etnias y por reconstruir en la pantalla los elementos de sus culturas: las lenguas, las tradiciones, las actividades de la vida cotidiana. La mayor debilidad de los discursos fílmicos es el haber evadido tomar una postura política. Lo hace de manera tangencial y, a mi juicio, muy pobre, El corazón del tiempo, pero en realidad los filmes no abordan los problemas importantes: la desigualdad, el racismo, el abandono por parte del gobierno, el costo de la resistencia... problemas que sí aborda el cine de no- ficción. Visto el problema de este modo, el cine mexicano de ficción todavía no ha logrado descolonizar la mirada.

13 Supongo que con este detalle, la película quiere subrayar que en la escuela no se emplea la lengua del pueblo. 


\section{El cine documental industrial: lo étnico como reproducción cultural y resistencia.}

Eco de la montaña (2014), el multipremiado documental de Nicolás Echevarría, un director con amplia experiencia en la filmación de los temas relacionados con la vida de las etnias ${ }^{14}$, trata del pueblo wixárica, de su cosmovisión, de la ritualidad que permite recrear constantemente no sólo "su" mundo, sino "el" mundo, de su arte y del desprecio y olvido gubernamental del que son objeto. Tangencialmente se toca el tema de las empresas que quieren apropiarse de su territorio para construir las minas ahí.

El personaje principal es Santos Motoapohua de la Torre, un artista huichol, quien a lo largo del filme está elaborando el mural "Viaje a Wirikuta" y quien también actúa como una especie de traductor cultural, al ir explicando los elementos simbólicos de la cosmología huichola y del sentido de la peregrinación que los "elegidos" de su pueblo realizan cada año. Su voz domina en todo el filme, de tal modo que lo que conocemos es su punto de vista y él, sin duda, es un defensor de la reproducción cultural, de la preservación de todas las tradiciones, que se consideran sagradas y, por tanto, obligatorias. Él y su familia dedican a ello cada momento de su vida.

Pero no todo sigue igual, como señalan algunos estudiosos y como lo muestra el mismo filme. Antes, todo el peregrinaje se realizaba a pie. Ahora se usan distintos tipos de transporte para trasladarse de un lugar a otro. Antes todo se hacía manualmente, ahora algunos elementos que se usan en las ceremonias se compran en las tiendas. De hecho, los procesos de negociación cultural, aún en

\footnotetext{
${ }^{14}$ Entre otros, 1973 - Judea: Semana Santa entre los Coras, 1979 - Tesgüinada, Semana Santa Tarahumara, 1979 - María Sabina, mujer espíritu, , Niño Fidencio, el traumaturgo del Espinazo 1981.
} 
esta etnia que ha tratado de cerrarse ante las influencias externas, según algunos estudiosos están muy avanzados. (Mizuno 138-170; Le Múr 172- 217). Influyen en ello el contacto con otras culturas indígenas, pero también el deseo de generar el interés de los turistas para venderles sus artesanías y así ganarse la vida. Este tema, sin embargo, tratado por los investigadores no se aborda en el filme. Lo que sí podemos apreciar, aun quienes no estamos muy familiarizados con la cultura wixárika, es que la ropa que se usa a diario e incluso durante las ceremonias, ahora contiene muchos menos bordados.

Sólo cuando Santos y su familia van a la Feria de Zacatecas, el hombre usa el traje tradicional con complejos y coloridos bordados. ¿Por qué ahí y no en las ceremonias? ¿Busca distinguirse entre una multitud de turistas? ¿Busca atraer su mirada?

El equipo de filmación agrega a la narración de Santos una magnífica fotografía que permite conocer el territorio que habitan los huicholes, desde La Sierra Madre Occidental hasta el desierto de San Luis Potosí, los lugares sagrados que se visitan durante la peregrinación, los rituales que se practican y relaciona todo lo anterior con el proceso de la elaboración del mural de Santos. En la banda sonora, además de las voces que hablan en español o en huichol, se escucha la música tradicional, los cantos, las plegarias y los ruidos incidentales. Algunas secuencias están acompañadas por la música compuesta para el filme por Mario Lavista.

El inicio del filme es impactante: se reproducen dos fragmentos de noticiario transmitido en 1997. En el primero se anuncia que:

una muestra de arte huichol adornará la estación del metro parisino Palacio Real, Museo de Louvre, en esta estación integrada al célebre museo que cuenta con una de las colecciones más importantes del mundo por la que transitan más de 8 millones de personas al año. El mural llamado "Pensamiento y alma huichol" será inaugurado en este lugar por 
CATEDRAL TomadA: Revista de crítica literaria latinoamericana / Journal of Latin American Literary Criticism La disputa por las identidades étnicas en el cine mexicano contemporáneo.

el presidente Ernesto Zedillo, quién vendrá a Francia a principios de octubre.

Inmediatamente nos percatamos de una ausencia: el nombre del artista quien elaboró la obra. Evidentemente, para el periodismo al servicio del gobierno no se trata propiamente del arte como el que alberga Louvre, sino de una suerte de arte menor, arte "étnico", que se realiza "artesanalmente" y por eso su lugar no es propiamente en el museo, sino el espacio público, el metro.

Un instante después vemos el momento de la inauguración: aparecen los presidentes Zedillo y Chirac con sus respectivas esposas y comitivas y... nadie más. Es cuando oímos por primera vez la voz de Santos quien explica: "Eso fue en la inauguración de la exposición y yo no estaba... se suponía que me iban a invitar pero no me invitaron. En vez de ir a Francia, me fui a mi tierra. A levantar la cosecha. Hasta por cierto que lo mal instalaron porque yo no lo coloqué".

Conforme a la película, para los huicholes el otro por excelencia es quien detenta el poder en el país: las instancias del gobierno y las empresas que quieren invadir sus tierras. Es de ellos de los que hay que defenderse, diferenciarse, es frente a ellos ante quienes hay que afirmar su identidad y tradiciones. Un helicóptero que se acerca a sus casas produce miedo ("pensábamos que eran los federales"). En otro momento, Santos, quien presenta su casa, a su familia y habla de su forma de vida, aclara "Aquí no tenemos estufas, ni luz, ni agua, ni cosas que ofrece el gobierno". Y mientras va realizando el mural explica la importancia de los peyotes y agrega "los peyotes están en el lugar sagrado. Pero aparte podemos poner un tigre y un toro. El toro somos nosotros. Estamos defendiendo el lugar sagrado. El tigre puede ser, a quien nada le importa el lugar sagrado, el presidente Calderón". ${ }^{15}$

La película marca con precisión los lugares en donde se encuentran Santos y su familia. El primero de ellos es Mesa del Venado en Jalisco. Ahí está su casa. La cámara registra el paisaje montañoso, la vegetación, las actividades cotidianas,

\footnotetext{
${ }^{15}$ Felipe Calderón fue presidente de México entre 2006 y 2012.
} 
nos presenta a cada miembro de la familia de Santos. Escuchamos la música que se toca en el lugar con instrumentos de cuerda.

En la vida cotidiana se trabaja, se convive con toda la familia, incluidas las hijas, los nietos y los dioses. Se les reza, se les piden bendiciones para alejar cualquier mal y se les rinden ofrendas. Lo que estructura la interacción entre los seres humanos y los elementos del universo es la reciprocidad. Así se expresa la solidaridad con los miembros de la comunidad familiar, pero también la vinculan con los seres del más allá, los ancestros, los dioses (Neurath 58-59).

Desde ahí, el filme nos traslada a Zacatecas, donde la familia va a divertirse en la Feria Nacional de Zacatecas de 2012. Después Santos va al Museo Zacatecano a ver la exposición del arte huichol, mira con detenimiento el mural que él mismo había realizado. Pero en otro momento irá, con su nieto mayor, al Museo de Arte Abstracto, donde admirará cada una de las obras monumentales y las interpretará conforme a su visión del mundo. La cámara recorre los majestuosos edificios y plazas coloniales.

El interés de los wixáricas por la creación de museos propios donde se exponga su arte y por las visitas a los museos de otras etnias y de otro tipo de arte, es algo que los distingue. Están, en efecto conscientes, de que para compartir el conocimiento entre los pueblos no sólo se requiere del discurso hablado, sino también de discurso visual, así como de la mostración de las diversas prácticas culturales.

Más tarde o, tal vez en otra ocasión, Santos recorre Zacatecas en compañía de Don Julio, quien es mara' akame, es decir un hombre iniciado, quien ocupa un cargo de autoridad dentro del gobierno tradicional y conduce todas las ceremonias religiosas. Los dos pasean, admiran iglesias, intercambian bromas y compran lo que Santos necesitará para hacer un mural y Don Julio para los rituales que se aproximan. Visten la ropa tradicional.

Esta narración está entrelazada con otra, en que se va mostrando una casa grande y casi vacía en la que Santos quiere montar un taller para trabajar. Una vez en el taller, el mara' akame hace el ritual de la limpieza tanto de las personas 
como de los distintos espacios de la casa. Para ello emplea plumas y recita las oraciones. Santos explica el plano general de su futura obra, cuya función será proteger el territorio de Wirikuta. Desde el principio vemos que se trata de una práctica compartida y de enseñanza. En todo el proceso participa, sobre todo, un sobrino de Santos, aunque también con frecuencia, su esposa.

Tras un corte, aparece la imagen de la sierra y un letrero informa que estamos en Cerro Quemado, Wirikuta. Es uno de los lugares sagrados, el lugar en que nació el sol. Mientras Santos cuenta el mito, la cámara muestra de manera alterna las imágenes del lugar y la obra que Santos está realizando: "un disco color blanco con alas y serpientes, con alas y patas", en sus propias palabras.

Vemos la peregrinación que los huicholes tienen que realizar cada año. Primero en un plano general y después de cerca: las personas pasan frente a la cámara fija en sus trajes tradicionales y tocando conchas y violines rústicos. Ya en el lugar realizan un ritual en que se canta y baila. Un letrero nos informa que dicho ritual formó parte del Consejo Regional Wixárica en defensa del territorio de Wirikuta, el 7 de febrero de 2012.

Mientras trabaja en el mural, Santos sigue contando los elementos de la cosmovisión huichola: sobre la inundación del mundo y de cómo ésta sólo afectó a los seres humanos, pero no a los dioses. Mientras cuenta cómo después surgieron en el mar las serpientes y las tortugas, podemos verlos plasmados en su obra, hecha en chaquira. En el centro hay una mujer, es la madre de los venados, que se comunica con el viento y con la lluvia. Así, la película introduce el tema fundamental para los huicholes: el agua y la lluvia. 


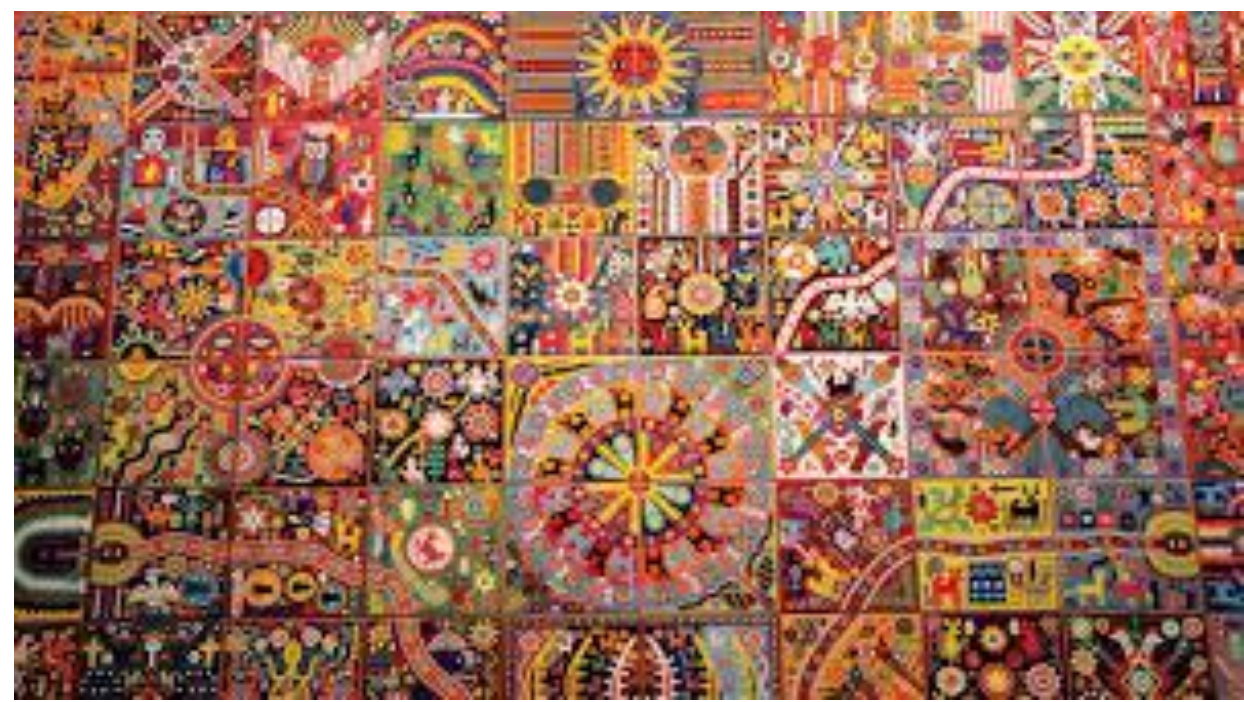

Santos y mara' akame, junto con un grupo de personas están en Tatei Matinieri, en San Luis Potosí. Todos mojan las manos en el manantial, se echan agua en la cara y en el cabello. "Esa agua es muy milagroso, explica Santos, es agua de la madre lluvia”. También dejan las ofrendas, las jícaras con comida, los tejidos que representan el "ojo de dios" y... una banderita mexicana.

La siguiente parada es en San Juan del Tzal, en San Luis Potosí, donde Santos compra un becerro. El grupo viaja en una camioneta donde termina amarrado el animal. Enseguida los vemos cortando la raíz de una planta, "ese palo es pintura facial, ese tiene mucho poder", explica Santos. Finalmente, buscan los peyotes y todo está listo para el ritual. Como explica E. Porras:

Por medio del contacto con los distintos lugares sagrados del desierto, al tomar el agua de Tatei Matinieri (manantial que se encuentra a la entrada de Wirikuta) y al ser bañados con ella por el guía de la peregrinación, al cortar la uxá (raíz de una planta que tiñe de amarillo cuando es tallada en una piedra y con la que dibujan en sus rostros signos de lluvia, venado, peyote, espirales, etcétera), y, sobre todo, a través de la cacería simbólica del peyote y de los efectos producidos por su ingestión, se profundiza la 
CATEDRAL TomadA: Revista de crítica literaria latinoamericana / Journal of Latin American Literary Criticism La disputa por las identidades étnicas en el cine mexicano contemporáneo.

liminalidad de los peregrinos, híkuritame, y la sensación de estar en otro mundo, en el de los antepasados y el de las visiones. (Porras 42)

En la película Mara'kame, bajo los efectos de peyote, habla en huichol. Su oración es traducida mediante los subtítulos:

Que surjan las palabras en otras bocas, las palabras de los dioses y los antepasados. A través de la cuerda se escucha la voz de los dioses.

Pido perdón si no puedo traducir bien las palabras de los ancestros. (llora) las gotas de mis lágrimas se convierten en rosas blancas . Pido perdón por haber guiado a extraños. Pero todos somos iguales. Que los dioses del sur rocíen agua bendita. Que la tierra donde existe el peyote sea siempre iluminada por las velas. Que las velas nos iluminen el camino para encontrar el peyote. Que el Dios del viento nos purifique, para llegar adonde hay peyote. Que seamos todos perdonados [...].

Ahora bien, ¿qué aporta la película a la representación de la identidad huichol? ¿Cómo construye su discurso?

Si bien se trata de un discurso complejo, basado en una estructura narrativa en que reconocemos más la experiencia fílmica de Echevarría que los modos de narrar wixáricas (Camacho-Padilla), las voces, las actividades cotidianas, rituales y artísticas de los miembros de la etnia tienen un papel protagónico. También está muy claro su propio punto de vista en todo lo que atañe a su identidad colectiva.

La película hace visible para un amplio público tanto la riqueza como el simbolismo de la cultura huichol y al mismo tiempo muestra su resistencia frente a los intentos de las empresas mineras de ocupar sus territorios. Su resistencia, que no es reciente, está ligada justamente a la idea de la conservación de la cultura, de su reproducción, aunque, como ya he dicho, el filme muestra también algunas innovaciones: la compra de objetos rituales o el hecho de que parte de la 
peregrinación se desarrolla en diversos medios de transporte. La fuerza política del discurso, descansa, sin embargo, en su fuerza estética. Las bellísimas imágenes de los paisajes y de los elementos simbólicos de la naturaleza, se entretejen con las imágenes de la obra de Santos de la Torre, de tal modo que el espectador puede apreciar tanto la influencia del simbolismo huichol en su arte, como las características propias del proceso creativo.

Los planos generales de los paisajes, en los que se aprecian diferencias notables entre la sierra y el desierto, alternan con los primeros planos de los rostros, de las manos capaces de trabajar la tierra, cortar la leña, lo mismo que hacer un trabajo finísimo insertando chaquira por chaquira en un dibujo previamente realizado. También son significativos los primeros planos de los pies ataviados con guaraches, mientras recorren el camino sagrado o mientras ejecutan las danzas rituales.

Uno de los logros del filme, además de los ya descritos, es su relación dialógica con la cultura de la etnia wixárica, gracias a lo cual no sentimos que el director del filme impuso su punto de vista. Eso acerca la película a las que voy a analizar más adelante.

\section{El cine documental comunitario y el conflicto de las identidades.}

¿A qué me refiero exactamente con el término "cine comunitario”? ¿En qué se diferencia de las otras formas de hacer el cine descritas en los apartados anteriores? Creo que puede caracterizársele a partir de los siguientes rasgos.

Es un cine que se hace de manera colectiva y no individual. Lo que se busca no es retratar al otro sino hacer este trabajo junto con él. Es un cine de bajo presupuesto o incluso, sin presupuesto: una cámara y un micrófono deben bastar. Eso también determina periodos cortos de filmación, la relativa simplicidad de la estructura narrativa, la dificultad para filmar de noche o en espacios cerrados donde se requeriría de un complejo manejo de la luz. 
Es un cine que tiene una motivación política transformadora que puede orientarse a diferentes fines prácticos y principalmente a contrainformar, a denunciar, a inducir a la participación social y coadyuvar a la construcción de la identidad colectiva (Mateos y Rajas 15-16).

En otros espacios he caracterizado el trabajo del colectivo Ojo de Agua Comunicación planteando, a partir del análisis de una muestra de las películas de su autoría ${ }^{16}$, que los cineastas o, más bien, videoastas, organizaron su relación con el otro fundamentalmente de manera tradicional (Jablonska). Lo más novedoso de las películas analizadas es que quienes hablan, en la mayoría de los casos, son personas que no tienen acceso a medios de comunicación para expresarse.

El otro habla en estos filmes sólo a través de la mirada y las instrucciones del cineasta. Las declaraciones son editadas, fragmentadas y dirigidas por el entrevistador. Sin embargo, desde el punto de vista de la representación de las identidades encontré que Ojo de Agua es capaz de mostrar procesos diferentes de identificación.

En algunos casos observamos la vuelta a una noción esencialista de la cultura e identidad. En otros casos se subraya la importancia del trabajo para la construcción identitaria, un trabajo no remunerado (tequio), preocupado por la conservación y rescate del medio ambiente. Sólo en un caso se reivindica el trabajo mecanizado, industrial, asociado a la mentalidad empresarial (Jablonska).

Algunos documentales, sobre todo los que se dedican a mostrar proyectos educativos alternativos, buscan mostrar procesos híbridos en los que se trata de rescatar y conservar los elementos de la tradición cultural, mezclándolos con algunos rasgos de lo que se considera como "cultura nacional", representada por los libros de texto oficiales y la "cultura global", simbolizada por la omnipresencia de las computadoras. Otro elemento que se reivindica con frecuencia es la práctica de la autogestión, de la asamblea, del ejercicio de los cargos comunitarios (Jablonska).

\footnotetext{
${ }^{16}$ En total Ojo de Agua realizó más de 100 documentales y yo analicé sólo 12 filmes.
} 
Finalmente, he analizado dos filmes que documentan los procesos de destrucción identitaria a cargo de las distintas instancias gubernamentales. Las denuncias hechas en estos filmes más que apuntar hacia un lamentable descuido por parte de un Estado que se ha asumido constitucionalmente como "multicultural" y asentado en sus pueblos originarios, permite más bien dar cuenta de una política deliberada que busca profundizar el círculo vicioso entre ser indígena, pobre, discriminado y tratado como delincuente. Una política que podríamos llamar como genocida (Jablonska).

Una película más reciente, Istmeño viento de rebeldía (2015) de Aléssi Dell' Umbria, podría verse como otro ejemplo de este tipo de cine, aunque fue realizada por un francés, que no pertenece a ningún colectivo y quien, sin embargo, hizo un documental con un pequeño equipo de filmación y con las etnias que viven el Istmo de Tehuantepec: los Ikoods y los Zapotecos.

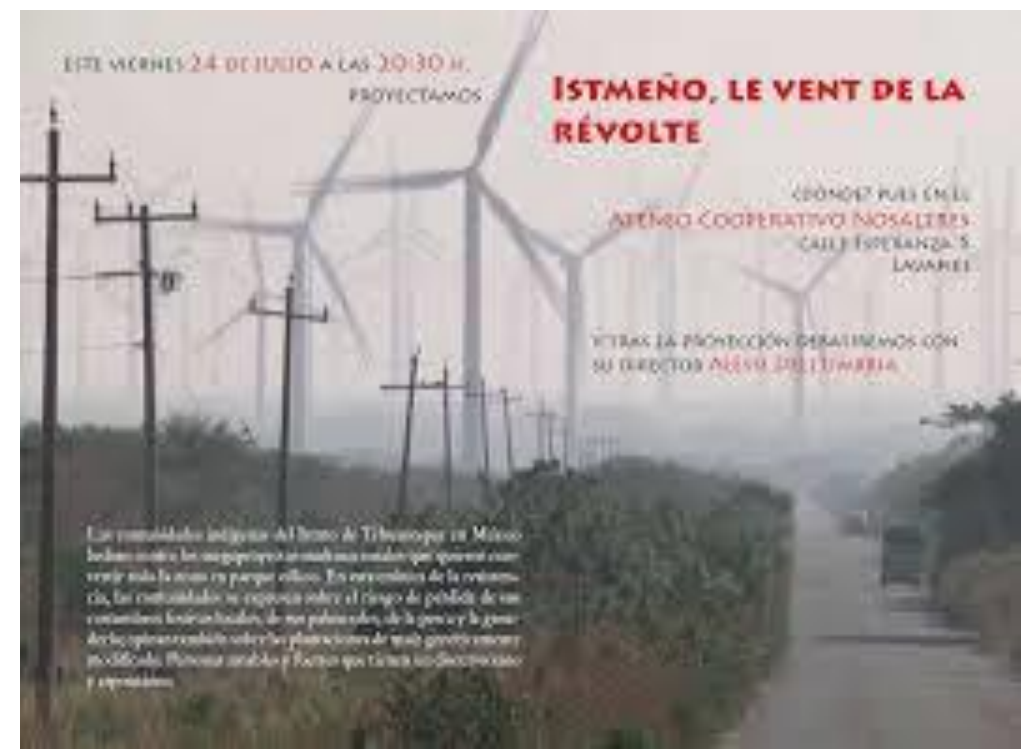

El tema central es la lucha de los pueblos del Istmo contra la construcción de los aerogeneradores en sus territorios. El cineasta les da la voz a los actores sociales. Aunque la edición final está seguramente hecha por él, las opiniones vertidas tanto en las lenguas propias, como en español, no responden al formato 
de "la entrevista". Se nota la confianza que la gente tiene con el cineasta. También es muy probable que vean la película como un instrumento más de su lucha.

¿Qué identidad reivindican los actores que aparecen en el filme? En realidad, se trata de una serie de atributos culturales que los pueblos reclaman frente al despojo y contaminación de sus territorios, la tierra, la costa y el mar, por parte de las empresas eólicas. A medida que la presión de las empresas y de los representantes del gobierno aumenta y la organización de los pueblos mejora, su identidad colectiva se va transformando. Tradicionalmente las dos etnias no se llevaban bien. De ello es prueba, entre otros, el conflicto de las denominaciones: "conocidos como "huaves" --que en lengua zapoteca significa "gente que se pudre en la humedad"-, ellos se hacen llamar Ikoots que en su lengua ombeayiiüds significa: "nosotros" (Vargas).

Pero ahora se van uniendo frente a una amenaza común y reivindican, cada vez más una identidad distinta: la del Istmeño. ¿De qué está hecha esta identidad? En primer lugar de la defensa de sus modos de vida, de la organización interna, de las actividades productivas (o de subsistencia) propias y de las creencias.

La vida de los pueblos istmeños transcurre en la comunidad, donde no hay propiedad privada, el dinero circula poco, el trabajo se realiza sin remuneración, en beneficio de todos (tequio). La máxima autoridad en las comunidades es la asamblea en que participan todos los comuneros. Ahí se toman las decisiones que después las autoridades elegidas deben acatar. Ahora, todo eso está bajo amenaza:

Nuestra población tenía ciertas particularidades, de comportamiento social, había más cohesión en el núcleo familiar, más cohesión en la cuestión comunitaria. Pero desde que estos megaproyectos empezaron, comenzó a desbaratarse esta armonía. Ya hay pleitos entre los mismos hermanos, entre compadres, amigos. Hay divisiones muy marcadas en muchas familias, que llegan a los tribunales. 
dice un hombre al inicio de la película.

Frente a la amenaza cada vez más pueblos deciden retornar a las viejas prácticas, reforzar el papel de las asambleas y defender sus formas de vida:

Somos asamblea, no somos líderes políticos corruptos que nos han vendido mil veces, de cualquier partido. Lo que exige la asamblea es el retiro de los aerogeneradores de nuestras tierras y de nuestras lagunas. Vivimos del pescado, del maíz, aun así tienen que comprar el maíz del extranjero. Qué va a pasar si les quitan más terrenos: matarlos, matar su vida. Matar la madre tierra, excavarlo, eso es matar nuestra vida [...].

declara una mujer.

Además de las asambleas crean cuerpos de vigilancia y de seguridad que trabajan de noche y de día.

Y, en efecto, las empresas eólicas matan sus formas tradicionales de producción. Las empresas desviaron las aguas y esto produjo erosión, además de que las aguas que ahora cruzan sus tierras traen aceites contaminantes de las turbinas que infectan las parcelas y se pierde la productividad. Tiran los árboles. Intentan privatizar las tierras que siempre han sido de uso común: por un lado, el palmar y el llano, por el otro las playas y manglares. En ello hay corrupción, asesinatos y quema de palmares.

También sufren los daños los pescadores, por la contaminación de las aguas, el ruido y el temblor que provocan las turbinas. Por el otro lado, proyectan en la noche una luz roja, que aleja los peces y los camarones. En las tierras dedicadas a la cría del ganado, se sufren los efectos de la erosión de la tierra, de la sequía.

Como en el caso del pueblo Wixárica, para los istmeños, el otro, son las diversas instancias gubernamentales y las empresas trasnacionales. Pero en el caso que estamos analizando, ya no es suficiente luchar por conservar los modos tradicionales de vida y las tradiciones. La defensa requiere de acciones más 
contundentes. Así que los istmeños ensayan formas de lucha legal, ante las instancias correspondientes, y también formas que el Estado considera como ilegales: marchas, mítines, plantones, barricadas. De las acciones colectivas relativamente aisladas, con el tiempo se pasa a formar un verdadero movimiento social, con estructuras basadas en las asambleas regionales y el diseño de las estrategias de lucha comunes.

Las marchas y los mítines sirven para articular la protesta, mostrar la fuerza al adversario y brindar la contrainformación. También la radio comunitaria busca concientizar a la gente:

Hay ya aproximadamente 698 aerogeneradores, se habla de que lo que quieren instalar en el Istmo de Tehuantepec es 5 mil aerógeneradores. Más bien da la impresión de que los políticos están actuando como empleados de las empresas trasnacionales. Da la impresión que los diputados, los presidentes municipales, por el lenguaje que utilizan, están pagados por las empresas trasnacionales.

De las movilizaciones van surgiendo consignas:

Fuera eólicas, viva Juchitán libre.

No al proyecto eólico, los pueblos indígenas exigimos respeto a nuestras tierras.

La tierra, el mar, el viento no se venden, se aman y se defienden.

En los mítines y marchas suena la música de otras luchas populares, como la canción de Víctor Jara: "Yo pregunto a los presentes/ Si no se han puesto a pensar/ Que esta tierra es de nosotros/Y no del que tenga más".

Pero también surgen expresiones propias, como los murales en que se compara la acción actual de las empresas (algunas de ellas españolas) con la Conquista. 
Otras formas de acción colectiva es la construcción de las barricadas y la toma de las carreteras para que la maquinaria de las empresas no pueda pasar. Ahí se llega a los enfrentamientos. Los comuneros, lo mismo hombres que mujeres, usan palos, resorteras y piedras y logran hacer retroceder a los policías.

Pero a medida que la represión aumenta, yambién empiezan a comprar armas. Un ganadero cuenta que una vez llevaba sus animales por la carretera: pasó una camioneta blanca con hombres de negro, con pasamontañas y dispararon cerca de ellos. "Dicen que no tenemos derecho de pasar por ahí. Pero antes si pasábamos. Soy mexicano, oaxaqueño, tengo derecho de pasar donde quiera. Sicarios se llaman, no? Ahorita ya compramos una arma, porque si los cabrones van a venir a buscarnos, tenemos que defendernos también".

¿Qué aporta la película al relato sobre la construcción de una nueva identidad, la del istmeño confrontado con el gobierno (municipal, estatal y federal), así como con las empresas eólicas, en defensa de sus territorios y formas de vida? Desde luego, las imágenes que nos permiten ver lo concreto. Mientras los estudios académicos sobre el problema señalan las tendencias, a los diversos actores en el conflicto y los motivos que tienen todos ellos para enfrentarse (Juárez- Hernández), la película nos muestra, mediante las imágenes muy poderosas la omnipresencia de los aerogeneradores. Las imágenes están tomadas de tal modo, que las enormes torres siempre ocupan el horizonte, se sobreponen a las construcciones de los pueblos, literalmente lo aplastan todo. La repetición de las imágenes de "los molinos" las convierte en un leitmotive visual, imposible de olvidar cuando se prenden las luces de la sala de cine.

Pero también podemos apreciar los paisajes naturales, la belleza de las dos lagunas, entre las cuales se encuentra la Barra de Santa Teresa, donde se quieren instalar más torres eólicas.

Finalmente, la película pone los rostros y dota de voces a los invisibles en esta contienda, a las mujeres, los hombres y los niños del Istmo. Ya no son números para nosotros sino personas que trasmiten su desesperación y coraje. Pero también demuestran su conocimiento de las leyes, que se quiebran 
constantemente cuando se trata de perjudicarlos a ellos, de la profunda corrupción, de los engaños de los que fueron víctimas cuando las empresas empezaron a llegar a la región y les dieron una información parcial y por lo tanto, falsa.

\section{Reflexiones finales.}

Vistas en su conjunto las películas hechas en México en lo que va del siglo XXI, han transformado no sólo el discurso sobre las identidades étnicas, sino que, en su mayoría, han buscado representarlas en forma dialógica, respetando el discurso del otro y mostrando que ese discurso tiene diversas dimensiones, no sólo verbales sin o también visuales, no sólo racionales, sino también míticas y simbólicas. Otro atributo de muchos de los filmes es el haber integrado dentro de la representación la totalidad del mundo indígena, incluyendo en ella, además de los hombres, mujeres y niños y sus diversas prácticas, a la naturaleza.

Muchas de ellas han logrado desfolklorizar nuestra visión de los pueblos indígenas. No buscan, como lo hacía el INI, "rescatar" los rituales como si éstos no estuvieran ligados a la totalidad de la vida de las etnias. Ya no fragmentan nuestra mirada, sino que tratan de mostrar el conjunto de los elementos que integran una determinada cultura: la organización política y las formas de ejercer el poder, la resistencia a las fuerzas que amenazan sus formas de vida, las formas de trabajo, los hábitos, las costumbres y la vida espiritual.

\section{Bibliografía}

Arroyo, Claudia, y Claudia Arroyo, et.al. "Imágenes de la nación en el melodrama revolucionario de la época de Oro: el caso de cine de Emilio Fernández"." México imaginado. Nuevos enfoques del cine 
(Trans)Nacional, Ciudad de México, Universidad Autónoma Metropolitana, 2011, 75-92.

Aumont, Jaques, et.al., Estética del cine. Espacio fílmico, montaje, narración, lenguaje. Barcelona, Paidós, 1999.

Ávila Irma y Alfonso Gumucio. “México”. El cine comunitario en América Latina y El Caribe, Bogotá, Fundación del Nuevo Cine Latinoamericano, 2012, pp. 371- 429.

Barrios, José Luis y Esther Acevedo. "El cine mexicano y el melodrama: velar el dolor, inventar la nación." Hacia otra historia del arte en México. La fabricación de arte nacional a debate (1920- 1959), III, Ciudad de México, Consejo Nacional para la Cultura y las Artes, CURARE, 2002, 217- 250.

Becerril, Alberto. "El cine de los pueblos indígenas en el México de los ochentas”. Revista Chilena de Antropología Visual, no. 25, 2015, pp. 30-49.

Camacho-Padilla, Sergio. "Narrativas de identidad como formas de resistencia en la construcción de la ciudadanía cultural en la Organización de Wixaritari. ” Instituto Tecnológico y de Estudios Superiores en Occidente, 2012.

Canet, Fernando y Josep Prósper. Narrativa audiovisual. Estrategias y recursos. Madrid, Síntesis, 2009.

Durand, Gilbert. Las estructuras narrativas del imaginario. México, Fondo de Cultura Económica, 2004

Friedlander, Judith. Ser indio en Hueyapan. Ciudad de México, Fondo de Cultura Económica, 1977.

Giménez, Gilberto. Estudios sobre la cultura y las identidades sociales, Consejo Nacional para la Cultura y las Artes, Ciudad de México, 2007.

Goncalves da Silva, Juliano. "Espejos del tiempo or mirrors of time? Cochochi, El Violín and Corazón de tiempo: the new saga of the indigenous Mexican cinema. ” Acenol. Revista de Antropología do Centro-Oeste, vol. 2, no. 3, 2015, pp. 102-122. http://periodicoscientificos.ufmt.br/ojs/index.php/aceno/article/view/2513. Accessed 2 Sep.2017.

Grüner, Edward. El conflicto de las identidades y el debate de la representación. La Plata, La Puerta, FBA, 2004.

Gutiérrez, Daniel y Helene Balsslev (coord.). Revisitar la etnicidad. Miradas cruzadas en torno a la diversidad. México, El Colegio de Sonora, Siglo XXI, 2008.

Hall, Stewart, et.al.. “Introducción: ¿quién necesita la identidad?”. Cuestiones de identidad cultural. Barcelona, Amorrortu, , 2011, 13- 39.

Jablonska, Aleksandra. La Conquista de América en el imaginario cinematográfico mexicano del fin de siglo (1970-1999). Tesis doctoral. Universidad Autónoma de Estado de México, 2005. . Cristales de tiempo: pasado e identidad en el cine mexicano contemporáneo (1970-1999). Ciudad de México, SEP, UPN, CONACYT, 2009. 
CATEDRAL TOMADA: Revista de crítica literaria latinoamericana / Journal of Latin American Literary Criticism La disputa por las identidades étnicas en el cine mexicano contemporáneo.

. "La construcción de las identidades en el documental indígena”. De Raíz Diversa, vol.2, no. 3, June 2015, 63-89.

http://biblioteca.clacso.edu.ar/Mexico/ppelunam/20160609093108/DRD_V1N3.pdf\#page=64.

Jablonska, Aleksandra, et.al. "La nación y su negación en el cine mexicano contemporáneo”. México imaginado. Nuevos enfoque en el cine

(Trans)nacional, Universidad Autónoma Metropolitana, Ciudad de México, 2011, 93- 115.

Le Múr, Rozen, et.al. "Los cuadros de estambre wixárica en el circuito turístico." La cultura wiráxica ante los desafíos del mundo actual. La negociación para la comunicación intercultural, Consejo Nacional para la Cultura y las Artes, Ciudad de México, 2015, 172- 217.

Maalouf, Amin. Identidades asesinas. Alianza Editorial, Madrid, 2007.

Mizuko, Noriko, et.al. "Los procesos de negociación cultural en los trajes bordados huicholes." La cultura wiráxica ante los desafios del mundo actual. La negociación para la comunicación intercultural, Ciudad de México, Consejo Nacional para la Cultura y las Artes, , 2015, 138- 170.

Neurath, Johannes. "El don de ver: El proceso de iniciación y sus implicaciones para la cosmovisión huichola” Desacatos, México, CIESAS, 2000, pp. 57-77.

Ochoa, María Guadalupe. La construcción de la memoria. Historia del documental mexicano. Ciudad de México, Consejo Nacional para la Cultura y las Artes, 2013.

Porras, Eugeni. "Algunos aspectos de las relaciones entre el desierto y los huicholes.", Culturales, vol. II, no, 3, Mexicali, 2006, pp. 32-51 http://www.redalyc.org/pdf/694/69420303.pdf

Santos, Boaventura de Sousa, "La reinvención del Estado y el Estado plurinacional”, Valladares de la Cruz, Laura, et.al (coord.), Estados plurales. Los retos de diversidad y la diferencia. México, Universidad Autónoma Metropolitana, Unidad Iztapalapa, Juan Pablos Editor, 2009, 157-180.

Terrén, Eduardo. "La etnicidad y sus formas: aproximación a un modo complejo de la pertenencia étnica”, Revista de Sociología, vol. 66, 2002, http://papers.uab.cat/article/view/v66-terren

Thompson, John. Ideología y cultura moderna. Teoría Crítica social en la era de la comunicación de masas. México. Universidad Autónoma Metropolitana, Unidad Xochimilco, 2002.

Valenzuela, José Manuel. Decadencia y auge de las identidades. Ciudad de México, El Colegio de la Frontera Norte/ Plaza y Valdés, 2004.

Vargas, Martín. "San Mateo de Mar: hablar, sentir y vivir la lengua ombeayiüts" http://www.nvinoticias.com/nota/51842/san-mateo-de-mar-hablar-sentir-yla-lengua-ombeayiuts, 2017.

Williams, Alan. Film and nationalism. Rutgers University Press, 2002, https://books.google.com.mx/books/about/Film_and_Nationalism.html?id= B-Qh9oZT6ggC\&redir_esc=y. 


\section{Filmografía}

Alazraki, Benito. Director. Balún Canán. CONACINE, 1977 https://es.wikipedia.org/wiki/Bal\%C3\%BAn Can\%C3\%A1n (pel\%C3\%A Dcula)

Cárdenas, Israel y Laura Guzmán. Directores. Cochochi, CONACULTAIMCINE, 2007, www.filos.unam.mx/seminarios/icdh/Cochochi.html

Carrasco, Salvador. Director. La otra conquista. 20th Century Fox, 1998, https://es.wikipedia.org/wiki/La_otra_conquista

Cortés, Alberto. Director. Corazón del tiempo, CONACULTA- IMCINE , 2008, https://corazondeltiempo.wordpress.com/

Dell' Umbria. Director. Istmeño, viento de rebeldía, 2015, https://argelaga.wordpress.com/2015/08/24/istmeno-viento-de-rebeldia-undocumental-de-resistencia-al-despojo/

Echevarría, Nicolás. Director. María Sabina, mujer espíritu. CONACULTAIMCINE, 1979, http://www.antropologiavisual.net/2012/maria-sabinamujer-espiritu/

Echevarría, Nicolás. Director. Tesgüinada, Semana Santa Tarahumara, CONACULTA- IMCINE, 1979, https://es.wikipedia.org/wiki/Nicol\%C3\%A1s_Echevarr\%C3\%ADa

Echevarría, Nicolás. Director. Niño Fidencio, el taumaturgo del Espinazo, CONACULTA- IMCINE 1981. https://es.wikipedia.org/wiki/Ni\%C3\%Blo_Fidencio,_el_taumaturgo_de_E spinazo

Echevarría, Nicolás. Director. Cabeza de Vaca. CONACULTA-IMCINE, 1990, http://cinemexicano.mty.itesm.mx/peliculas/cabezavaca.html

Echevarría, Nicolás. Director. Eco de la montaña, CONACULTA-IMCINE, 2014, http://www.yaconic.com/eco-de-la-montana-de-nicolas-echevarria/ Gavaldón, Roberto. Director. Macario. https://es.wikipedia.org/wiki/Macario_(pel\%C3\%ADcula)

Cazals, Felipe. Director. El jardín de tía Isabel. http://www.imcine.gob.mx/cinemexicano/pelicula2322

Olhovich, Sergio. Director. Bartolomé de las Casas, CONACULTA- IMCINE, 1992, http://www.imcine.gob.mx/cine-mexicano/pelicula1180 